\title{
X-band COSMO-SkyMed wind field retrieval, with application to coastal circulation modeling
}

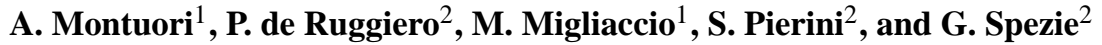 \\ ${ }^{1}$ Dipartimento per le Tecnologie, Università di Napoli Parthenope, Naples, Italy \\ ${ }^{2}$ Dipartimento di Scienze per l'Ambiente, Università di Napoli Parthenope, Naples, Italy
}

Correspondence to: A. Montuori (antonio.montuori@uniparthenope.it)

Received: 21 September 2012 - Published in Ocean Sci. Discuss.: 16 October 2012

Revised: 14 January 2013 - Accepted: 16 January 2013 - Published: 14 February 2013

\begin{abstract}
In this paper, X-band COSMO-SkyMed ${ }^{(}$synthetic aperture radar (SAR) wind field retrieval is investigated, and the obtained data are used to force a coastal ocean circulation model. The SAR data set consists of $60 \mathrm{X}$-band Level 1B Multi-Look Ground Detected ScanSAR Huge Region COSMO-SkyMed ${ }^{\circledR}$ SAR data, gathered in the southern Tyrrhenian Sea during the summer and winter seasons of 2010. The SAR-based wind vector field estimation is accomplished by resolving both the SAR-based wind speed and wind direction retrieval problems independently. The sea surface wind speed is retrieved by means of a SAR wind speed algorithm based on the azimuth cut-off procedure, while the sea surface wind direction is provided by means of a SAR wind direction algorithm based on the discrete wavelet transform multi-resolution analysis. The obtained wind fields are compared with ground truth data provided by both ASCAT scatterometer and ECMWF model wind fields. SAR-derived wind vector fields and ECMWF model wind data are used to construct a blended wind product regularly sampled in both space and time, which is then used to force a coastal circulation model of a southern Tyrrhenian coastal area to simulate wind-driven circulation processes. The modeling results show that X-band COSMO-SkyMed ${ }^{\circledR}$ SAR data can be valuable in providing effective wind fields for coastal circulation modeling.
\end{abstract}

\section{Introduction}

Accurate and appropriate measurements of the wind vector field over the sea surface are of great relevance in the oceanographic, meteorological and climatic research, and for the improvement of short-term forecast and warning (Janssen, 2004). In fact, the wind is a key parameter in the momentum exchange between the atmospheric boundary layer and the sea surface, which in turn drives the circulation and mixing of seawater (e.g., Vallis, 2006). The capability and the increasing need to retrieve the wind field at sea with both high spatial-temporal resolution and continuity can improve the ocean circulation modeling, especially in coastal areas, where the changes of the local winds depend crucially on the local coastal orography and land/sea thermal conditions.

The wind field over the sea surface is classically inferred by means of either meteorological models or in situ measurements, which unfortunately suffer from both technical and physical constraints that severely affect spatial-temporal coverage and resolution of the resulting wind field product (Bentamy et al., 1999; Migliaccio and Reppucci, 2006). In addition to these widely used wind field data, microwave remote sensing has shown the capability of providing sea surface wind fields with mesoscale resolution and with short revisiting time. Within such a framework, the key sensor is the active satellite-based microwave scatterometer, which provides wind field measurements at sea by means of a nonlinear inversion scheme, which requires both an accurate tailored geophysical model function (GMF) and an appropriate set of sea surface normalized radar cross-section (NRCS) measurements at different azimuth angles (Bentamy et al., 1999; Migliaccio and Reppucci, 2006). The GMF, which is not a "universal model", relates the NRCS measurements of the sea surface roughness to the local wind field at sea, taking into account both the specific sensor parameters (e.g., polarization, frequency, incidence angle, etc.) and sea state conditions. Actually, scatterometer-based missions, such as the 
QuikSCAT (unavailable after November 2009) and the Advanced Scatterometer (ASCAT) ones, have been providing operational wind products with a spatial gridding resolution ranging from $25 \mathrm{~km} \times 25 \mathrm{~km}$ to $12.5 \mathrm{~km} \times 12.5 \mathrm{~km}$, respectively (Yang et al., 2011). These products are not properly suitable for some marine applications, especially in coastal and near shore areas, where they suffer from uncertainty and large wind field estimation errors due to their large footprint (Bentamy et al., 1999; Migliaccio and Repucci, 2006; Yang et al., 2011).

In this context, the possibility to retrieve the sea surface wind field from synthetic aperture radar (SAR) images, with high resolution and in areas where the scatterometer measurements fail, is very interesting from an operational viewpoint. SAR is an active, microwave, band-limited sensor able to provide daytime and nighttime high-resolution NRCS measurements of the observed marine scenes with a synoptic view, and almost independently of atmospheric conditions (Jackson and Apel, 2004; Migliaccio and Reppucci, 2006). It has long been known that the wind field generates an anisotropic sea roughness, which can in principle be explained by means of a two-scale scattering model (Nunziata et al., 2007), where both centimeter resonant waves and longwaves can be directly and indirectly observed, respectively. The physical interaction between the electromagnetic waves and the sea surface at the SAR resolution scale is generally nonlinear, and accounts for complex interactions between the sea surface and atmosphere (Jackson and Apel, 2004). This makes the physical problem much more complicated than the scatterometer one. However, the use of SAR measurements allows one to resolve the wind co-location problem, which generally introduces further errors, as in the case of SAR oil spill monitoring. Moreover, the high-spatial and temporal resolution provided by each SAR sensor, together with both the ground coverage and the short revisit-time provided by the recently launched SAR constellations, makes this sensor a key alternative source of sea surface wind field information able to integrate classical wind field estimation techniques, such as meteorological models, in situ observations and scatterometers (Migliaccio and Repucci, 2006; Yang et al., 2011).

In connection with the SAR-based wind field retrieval at sea, the use of X-band COSMO-SkyMed ${ }^{\circledR}$ SAR data is highly innovative. The Italian Space Agency COSMO-SkyMed ${ }^{\complement}$ is a constellation of four satellites equipped with X-band SARs, which ensures both wide area coverage and a small revisit time (Italian Space Agency, 2007). Among the different COSMO-SkyMed ${ }^{\circledR}$ SAR acquisition modes, i.e., Spotlight, StripMap and ScanSAR modes, the ScanSAR Huge Region mode is very interesting from an operational viewpoint, especially for both coastal circulation and oceanographic applications. In fact, it allows achieving a large ground coverage of about $200 \mathrm{~km} \times 200 \mathrm{~km}$ with a spatial resolution of $100 \mathrm{~m} \times 100 \mathrm{~m}$ in both range and azimuth directions (Italian Space Agency, 2007). However, the sea surface wind field estimation through X-band SAR measurements is a non-trivial task since, at higher frequencies, severe weather conditions and atmospheric phenomena drastically compromise SAR image interpretations for sea surface wind field estimation purposes (Lee et al., 1995).

Classical SAR-based wind field retrieval techniques are based on the use of a scatterometer-derived GMF approach (Horstmann et al., 2003; Jackson and Apel, 2004; Migliaccio and Reppucci, 2006). They provide the wind speed estimation at sea when both well-calibrated sea surface NRCS measurements and a priori knowledge of wind direction information are provided, together with the availability of a tailored GMF accounting for both sensor parameters and sea state conditions (Horstmann et al., 2003; Jackson end Apel, 2004; Migliaccio and Reppucci, 2006). In this context, the wind direction information can be provided from either external information (e.g., meteorological model, buoy measurements, etc.) or SAR-based wind direction retrieval techniques (e.g., spectral-, wavelet- and gradient-based approaches) (Horstmann et al., 2003; Jackson and Apel, 2004; Migliaccio and Reppucci, 2006). Since in many operational SAR-based applications (e.g., the traffic routes monitoring and the oil field observation) the end-user can be basically interested to know either the wind speed or the wind direction information only, it is useful to carry out the SAR-based wind field retrieval at sea by resolving both the SAR wind speed and wind direction estimation problems independently. Within such a context, a SAR wind speed algorithm based on the azimuth cut-off procedure has been developed for Cband ERS SAR data only (Chapron et al., 1995; Kerbaol et al., 1998; Korsbakken et al., 1998), which allows providing consistent wind speed estimations at sea without requiring a priori knowledge of the wind direction and the calibration accuracy of SAR NRCS measurements.

In this context, in this paper, the capabilities of X-band COSMO-SkyMed $^{\circledR}$ SAR data are investigated for sea surface wind vector field retrieval purposes, with application to coastal circulation modeling. The SAR data set consists of $60 \mathrm{X}$-band VV-polarized Level 1B MultiLook Ground Detected (DGM) ScanSAR Huge Region mode COSMO-SkyMed ${ }^{\complement}$ SAR data, gathered in a southern Tyrrhenian coastal area during the summer and winter seasons of 2010. The oceanographic model used in the simulations is the sigma-coordinate free-surface Princeton Ocean Model (POM, Blumber and Mellor, 1987; Mellor, 2003), which is particularly suitable to model the marine circulation in coastal areas connected with a deep basin. The SAR-based wind field retrieval is here accomplished by resolving the SAR-based wind speed and wind direction estimation problems, independently. On one hand, the SAR wind speed estimation is accomplished by means of a SAR wind speed retrieval algorithm based on the azimuth cut-off procedure (Chapron et al., 1995; Kerbaol, 
1998; Korsbakken et al., 1998; Migliaccio et al., 2012; Montuori et al., 2012). On the other hand, the SAR wind direction estimation is accomplished by means of SAR wind direction retrieval algorithm based on the discrete wavelet transform multi-resolution analysis (DWT-MRA) (Du et al., 2002). The effectiveness of COSMO-SkyMed ${ }^{\complement}$ SAR measurements for sea surface wind field retrieval purposes is analyzed and compared with both ASCAT scatterometer wind fields (http://podaac.jpl.nasa.gov) and European Centre for Medium-Range Weather Forecasts (ECMWF) model data (http://www.ecmwf.int/), respectively. Finally, the possibility to force the POM by means of a blended wind field product, provided by both COSMO-SkyMed ${ }^{\odot}$ SAR wind field estimation and ECMWF model data, is properly investigated and discussed.

The paper is organized as follows: in Sect. 2, the methodology and the theoretical background at the basis of the X-band SAR wind field retrieval approach is described. In Sect. 3, some significant experimental results are presented, which are relevant to the X-band COSMO-SkyMed ${ }^{\circledR}$ SAR-based wind field estimation; the comparison with both ASCAT scatterometer and ECMWF model ground truth data is then carried out. In Sect. 4, the coastal circulation model is presented and the results obtained with the blended wind product are discussed. Finally, in Sect. 5 conclusions are drawn.

\section{X-band SAR wind field retrieval methodology}

In this section, the methodology and the theoretical background at the basis of the X-band SAR-based wind field retrieval approach is described and specialized for X-band VV-polarized Level 1B DGM ScanSAR Huge Region mode COSMO-SkyMed ${ }^{\circledR}$ SAR data.

Two independent steps are conceived for X-band COSMO-SkyMed ${ }^{\circledR}$ SAR wind field retrieval purposes: (1) the pre-processing analysis and (2) the SAR-based wind field estimation.

\subsection{Pre-processing analysis}

The pre-processing analysis is accomplished to improve both the image quality of X-band ScanSAR Huge Region mode COSMO SkyMed ${ }^{\circledR}$ SAR measurements and the subsequent SAR-based wind field estimation, which strongly relies on the SAR data quality. Within such a framework, two different phenomena must be dealt with, which severely impact the SAR image interpretation for wind field estimation purposes, i.e., the scalloping and the atmospheric/tropospheric phenomena. The scalloping is related to the peculiar burst acquisition mode of ScanSAR SAR measurements (Holzner and Bamler, 2002; Schiavulli et al., 2011, 2012). It consists of periodic processing anomalies along with the azimuth direction, which appear as thin horizontal bars in SAR imagery and therefore may severely affect the accuracy of SAR-based wind field estimation (Holzner and Bamler, 2002; Schiavulli et al., 2011, 2012). The atmospheric/tropospheric phenomena (e.g., rain cells, cloud coverage, oceanic fronts, convective cells, etc.) are conversely related to the X-band acquisition frequency of SAR data (Lee et al., 1995). They appear as non-homogeneous areas in marine SAR images and, especially at higher frequencies, can severely compromise both the SAR imagery interpretability and then the retrieval of wind field at sea (Lee et al., 1995).

With this respect, the pre-processing analysis of X-band ScanSAR COSMO-SkyMed ${ }^{\complement}$ SAR data is accomplished by means of the automatic two-step pre-processing procedure presented in Schiavulli et al. (2011), which is here adopted to effectively improve the quality of SAR images. The first sub-step of the proposed approach aims at removing the scalloping pattern in X-band ScanSAR COSMO-SkyMed ${ }^{\circledR}$ SAR data by means of a filtering technique based on the discrete wavelet transform multi-resolution analysis (DWT-MRA) (Mallat, 1989; Schiavulli et al., 2011, 2012). This technique allows both enhancing and then removing the spectrum harmonics of SAR images, which are related to the directional features of the scalloping pattern. The second sub-step of the proposed approach conversely implements the homogeneity test described in Schultz-Stellenfleth et al. (2004) and Schiavulli et al. (2011), which, based on the variance to mean square ratio (VMSR) of SAR image power spectral density, allows detecting and then removing all the non-homogeneous areas (such as marine areas with ships, coastline, atmospheric fronts and more generally atmospheric phenomena) over the homogeneous marine background in X-band SAR images.

\subsection{SAR-based wind field estimation}

Following the pre-processing analysis, the SAR-based wind field estimation is achieved by resolving both the SAR-based wind speed and wind direction retrieval problems, independently.

The SAR-based wind speed estimation is accomplished by using a SAR wind speed algorithm based on the azimuth cutoff procedure (Chapron et al., 1995; Kerbaol et al., 1998; Korsbakken et al., 1998, Migliaccio et al., 2012; Montuori et al., 2012). The proposed approach accounts for the relationship between the sea surface wind field and the smearing effects in the SAR images, which strongly depends on both sensor's parameters (e.g., platform altitude, velocity, etc.) and sea state conditions (Chapron et al., 1995; Kerbaol et al., 1998; Korsbakken et al., 1998). In simple terms, the SAR sensor behaves like a Gaussian-shaped low-pass filter, which induces a cut-off along the azimuth direction, and therefore limits the shortest detectable azimuth cut-off wavelength $\lambda_{c}$. The latter accounts for sea waves orbital motions responsible for the smearing effects within the SAR imagery and therefore can be considered a robust indicator of sea surface wind speed (Chapron et al., 1995; Kerbaol et al., 1998; Korsbakken et al., 1998). Based on this rationale, a SAR wind 
speed algorithm based on the azimuth cut-off procedure has been developed and tested for C-band SAR data (Chapron et al., 1995; Kerbaol, 1998; Korsbakken et al., 1998), where $\lambda_{\mathrm{c}}$ is physically related to the sea surface wind speed according to the following linear semi-empirical model:

$U_{10}=\alpha\left(\lambda_{\mathrm{c}}-\Lambda\right)$,

where $U_{10}\left(\mathrm{~m} \mathrm{~s}^{-1}\right)$ is the wind speed at $10 \mathrm{~m}$ above the sea surface, $\Lambda(\mathrm{m})$ is the SAR nominal azimuth resolution and $\alpha\left(\mathrm{s}^{-1}\right)$ is an empirical parameter. The proposed approach allows resolving the SAR wind speed estimation problem, without requiring both any wind direction information and the calibration accuracy of SAR NRCS measurements, which conversely characterize GMF-based SAR wind field retrieval approaches. Although the design of this algorithm has been developed only at C-band, in Kerbaol and Collard (2005), the physical suitability of the proposed approach was already foreseen at X-band.

In this paper, the X-band SAR wind speed estimation is obtained by using the X-band azimuth cut-off model function presented in Migliaccio et al. (2012) and Montuori et al. (2012), which has been successfully derived and tested to X-band VV-polarized Level 1B DGM ScanSAR Huge Region mode COSMO-SkyMed ${ }^{\circledR}$ SAR measurements.

The SAR-based wind direction estimation is obtained by means of the SAR wind direction algorithm based on the DWT-MRA (Du et al., 2002; Schiavulli et al., 2011). The proposed approach retrieves the wind direction at sea by finding those wind-induced pattern texture features that are visible in SAR imagery as image streaks aligned to the sea surface wind direction. The streaks, which appear as adjacent periodic bands of bright and dark radar returns, are interpreted as manifestations of either atmospheric boundary layer (ABL) rolls (especially for high wind and/or unstable atmospheric conditions, in both high and mid-latitude regions) or other marine features, such as streaks from foam or, more generally, marine surfactants (Du et al., 2002; Horstmann et al., 2002; Schiavulli et al., 2011). Since windinduced streaks are usually meant to be aligned with the mean wind field at the sea (Du et al., 2002; Horstmann et al., 2002; Schiavulli et al., 2011), it is possible to retrieve the sea surface wind direction by simply retrieving the orientations of these wind-induced phenomena. The processing chain of the SAR wind direction retrieval technique is detailed in Du et al. (2002) and Schiavulli et al. (2011). It must be pointed out that SAR-based wind directions estimated with the DWTMRA approach still contain an inherent $180^{\circ}$ wind direction ambiguity. The latter is properly resolved either if wind shadowing (often visible in the lee of objects) is present in SAR imagery or by using external information, such as the ASCAT scatterometer data.

\section{X-band COSMO-SkyMed SAR wind field retrieval results}

In this section, some significant experimental results are presented, which are relevant to the sea surface wind vector field estimation over X-band VV-polarized Level 1B DGM ScanSAR Huge Region COSMO-SkyMed ${ }^{\circledR}$ SAR measurements and their subsequent comparison with both ASCAT scatterometer and ECMWF model wind fields.

The X-band SAR data set consists of $60 \mathrm{X}$-band Level 1B DGM ScanSAR Huge Region mode VV-polarized COSMO-SkyMed $^{\circledR}$ SAR data, gathered in a southern Tyrrhenian coastal area during the summer and winter seasons of 2010 (Italian Space Agency, 2007). Each SAR acquisition provides ground coverage of about $200 \mathrm{~km} \times 200 \mathrm{~km}$ with a spatial resolution of $100 \mathrm{~m} \times 100 \mathrm{~m}$ and a pixel spacing of $50 \mathrm{~m} \times 50 \mathrm{~m}$, in both range and azimuth direction respectively. The ground truth, which is used as reference wind field for comparison purposes, is provided by timely and spatially co-located ASCAT scatterometer wind fields (with a spatial gridding resolution of $12.5 \mathrm{~km} \times 12.5 \mathrm{~km}$ ) and ECMWF ERA Interim Reanalysis model data (with a horizontal resolution of $1 / 4^{\circ}$, which corresponds to $\sim 28 \mathrm{~km}$ along a meridian and, in the area under consideration, to $\sim 20 \mathrm{~km}$ along a parallel), respectively. Since both the ASCAT scatterometer wind field and the ECMWF model data are often not timely co-located with respect to the SAR image acquisition, a linear interpolation in time is accomplished between both the ground truth reference wind field data acquired before and after the SAR acquisition time, thus providing the timely co-located reference wind field.

A single experiment is fully detailed, to demonstrate the effectiveness of the X-band VV-polarized Level 1B DGM ScanSAR Huge Region mode COSMO-SkyMed ${ }^{\circledR}$ SAR data for sea surface wind field estimation purposes. The analysis is properly accomplished by comparing the $\mathrm{X}$-band COSMO-SkyMed ${ }^{\circledR}$ SAR-derived wind speed and wind direction retrievals with respect to the reference ground truth. A SAR-based wind field retrieval gridding scale of $12.5 \mathrm{~km} \times 12.5 \mathrm{~km}$ is considered. Therefore, the timely colocated reference ground truth provided by ECMWF model wind fields is bi-linearly interpolated in space over both the ASCAT scatterometer and the SAR-based wind field gridding scale, for comparison and validation purposes.

The experiment refers to the X-band COSMO-SkyMed ${ }^{\circledR}$ SAR acquisition of 20 November 2010 at 05:00 UTC. The VV-polarized NRCS image is shown in gray tones in Fig. 1a. The output of the pre-processing step is shown in Fig. 1b, where the scalloping, the atmospheric phenomena and other non-homogeneous areas in the SAR image are successfully detected and removed from the homogeneous marine background. The timely and spatially co-located ASCAT scatterometer and ECMWF model wind speed data are shown in Fig. 2a-b, respectively, where notable differences appear, 


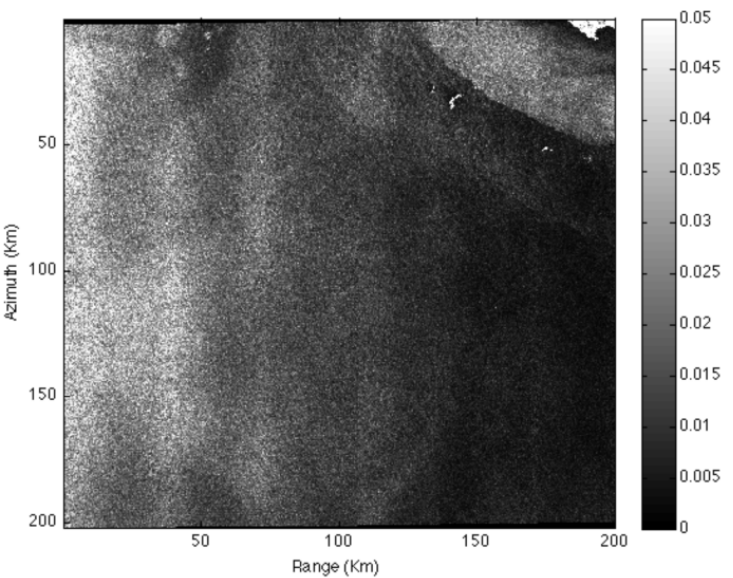

(a)

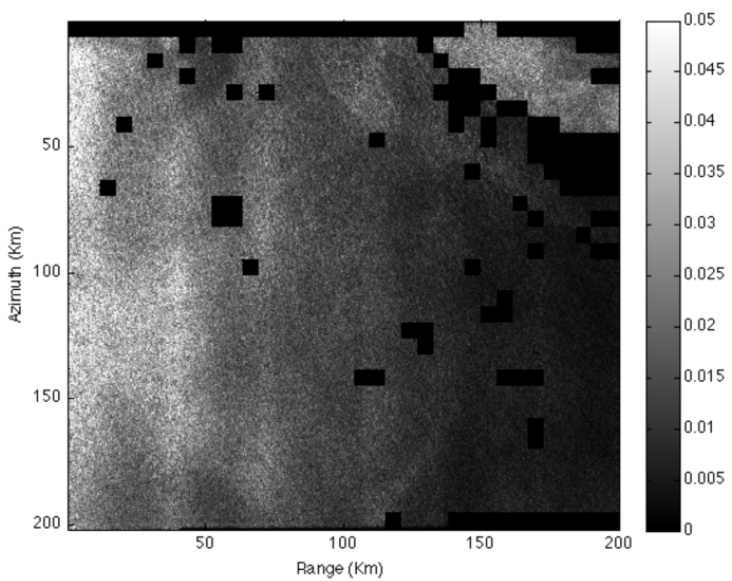

(b)

Fig. 1. X-band Level 1B DGM ScanSAR Huge Region COSMO-SkyMed ${ }^{\complement}$ SAR data acquired on 20 November 2010 at 05:00 UTC. (a) VV-polarized NRCS. (b) Output of the pre-processing step of the SAR wind field retrieval approach.

Table 1. COSMO-SkyMed ${ }^{\complement}$ SAR-ASCAT-ECMWF wind field products inter-comparison in terms of RMSE, $\mu$ and $\sigma$ values.

\begin{tabular}{|c|c|c|c|c|c|c|}
\hline \multirow[b]{3}{*}{ Product comparison } & \multicolumn{6}{|c|}{ Variable } \\
\hline & \multicolumn{3}{|c|}{ Wind Speed $\left(\mathrm{m} \mathrm{s}^{-1}\right)$} & \multicolumn{3}{|c|}{ Wind direction $\left(^{\circ}\right)$} \\
\hline & RMSE & $\mu$ & $\sigma$ & RMSE & $\mu$ & $\sigma$ \\
\hline COSMO-SkyMed $^{\circledR}$ SAR vs. ASCAT & 2.27 & -0.59 & 2.19 & 18.95 & 1.71 & 18.88 \\
\hline COSMO-SkyMed ${ }^{\circledR}$ SAR vs. ECMWF & 3.30 & -1.69 & 2.83 & 23.85 & 7.54 & 22.63 \\
\hline ASCAT vs. ECMWF & 2.71 & -1.48 & 2.28 & 23.24 & 4.69 & 22.76 \\
\hline
\end{tabular}

especially along the coastal area. This result can be explained by considering the different spatial gridding resolution of the two different wind speed products, demonstrating that the ECMWF model data suffer from more uncertainty over the maritime coastal areas with respect to the ASCAT scatterometer wind speed. The output of the X-band COSMO-SkyMed $\left.{ }^{(}\right)$SAR wind speed retrieval approach based on the X-band azimuth cut-off procedure is shown in Fig. 2c. The comparison between the X-band SAR-based azimuth cut-off wind speed estimation and the reference ground truth shows a fair agreement (especially with respect to the ASCAT scatterometer reference wind speed) with root-mean-square error (RMSE) values equal to $2.1 \mathrm{~m} \mathrm{~s}^{-1}$ and $4 \mathrm{~m} \mathrm{~s}^{-1}$ with respect to the ASCAT scatterometer and the ECMWF model wind speed, respectively. A further comparison is provided between the ASCAT scatterometer and the ECMWF model wind speeds, which provides a RMSE value of $2.8 \mathrm{~m} \mathrm{~s}^{-1}$. It can be noted that non-negligible differences in terms of sea surface wind speed are present along the coastal area of SAR image domain, for both the ASCAT scatterometer and the ECMWF model ground truth wind speed. This result takes into account that the reference wind speed data (especially the ECMWF model one) both suffer from uncertainty over the maritime coastal areas and they are not able to capture small-scale features, which can in turn be revealed by means of SAR data. Experimental results further demonstrate both the high-resolution accuracy of the ASCAT scatterometer wind speed with respect to the ECMWF model data (especially along the coastal areas) and the consistency of X-band COSMO-SkyMed ${ }^{\complement}$ SAR-derived wind speed product especially with respect to the ASCAT scatterometer ground truth.

The output of the X-band COSMO-SkyMed ${ }^{\circledR}$ SAR wind direction retrieval approach based on the DWT-MRA is shown in Fig. 2d-e together with the timely and spatially colocated ASCAT scatterometer and ECMWF model ground truth, respectively. The comparison between the X-band SAR-based DWT-MRA wind direction estimation and the reference ground truth shows a fair agreement (especially with respect to the ASCAT scatterometer reference wind direction) with $\mathrm{RMSE}$ values equal to $16^{\circ}$ and $24^{\circ}$ with respect to the ASCAT scatterometer and the ECMWF model wind directions, respectively. A further comparison is provided between the ASCAT scatterometer and the ECMWF model wind directions (see Fig. 2f), which provides a RMSE value of $21^{\circ}$. Moreover, in Fig. 3 the three comparisons of Fig. 2 are shown in georeferenced maps in terms of the complete wind vector field. In conclusion, these results demonstrate 


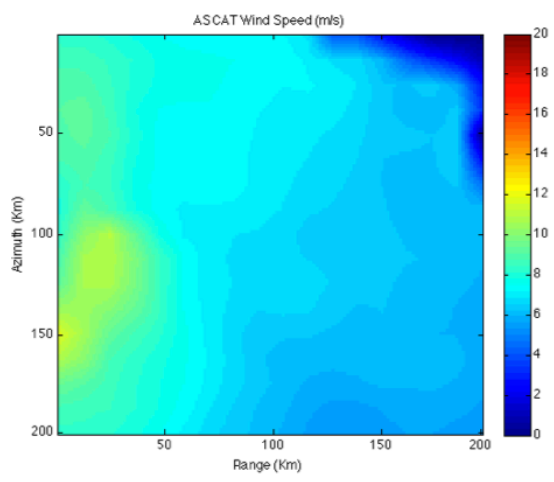

(a)

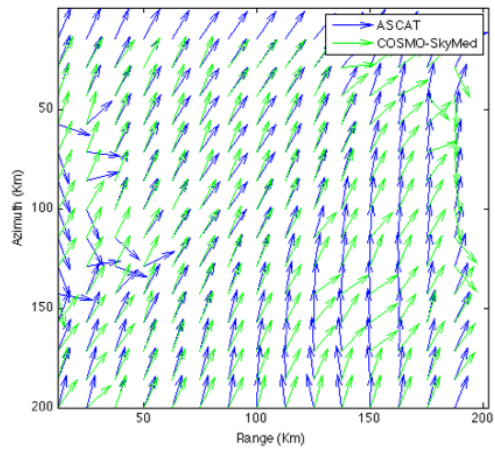

(d)

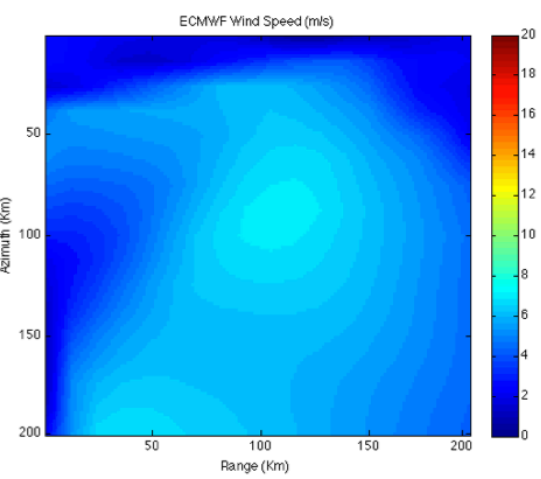

(b)

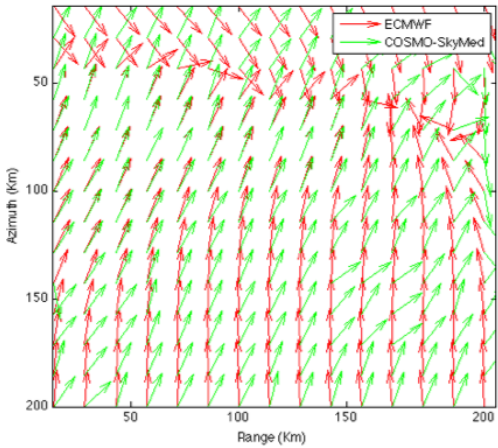

(e)

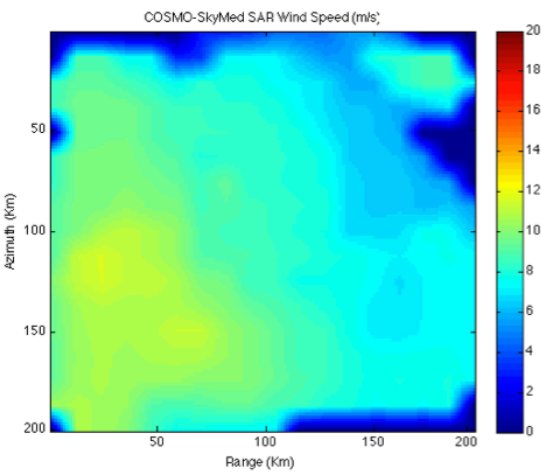

(c)

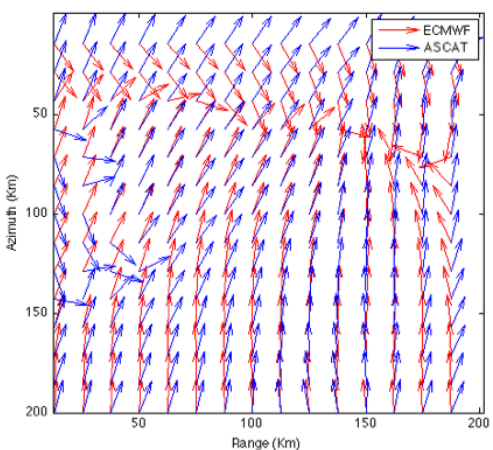

(f)

Fig. 2. Wind field retrieval of the X-band VV-polarized Level 1B DGM ScanSAR Huge Region COSMO-SkyMed ${ }^{\circledR}$ SAR data acquired on 20 November 2010 at 05:00 UTC. (a) Reference ASCAT scatterometer wind speed. (b) Reference ECMWF model wind speed. (c) SAR-based wind speed estimation over a sub-image scale of $12.5 \mathrm{~km} \times 12.5 \mathrm{~km}$. (d) SAR-based wind direction estimation together with the reference ASCAT scatterometer wind direction. (e) SAR-based wind direction estimation together with the reference ECMWF model wind direction. (f) ASCAT scatterometer wind direction together with the ECMWF model data.

both the high-resolution accuracy of the ASCAT scatterometer wind direction (especially along the coastal areas) with respect to the ECMWF model data and the consistency of COSMO-SkyMed ${ }^{\circledR}$ SAR wind direction retrievals, especially with respect to the ASCAT scatterometer winds.

Other meaningful results are summarized in Fig. 4 and Table 1, where the three different wind field products (i.e., from SAR, scatterometer and model data) are properly compared for the whole processed COSMO-SkyMed ${ }^{\circledR}$ SAR data set. These results agree with the previous ones, thus demonstrating the effectiveness of both the X-band azimuth cutoff model function and the DWT-MRA technique presented in Sect. 2 to obtain consistent wind speed and wind direction estimation, respectively, even through X-band SAR data. Furthermore, experimental results show the full benefits of X-band Level 1B DGM ScanSAR Huge Region mode COSMO-SkyMed $^{\circledR}$ SAR data as an alternative source of wind field estimation.

\section{Application to coastal circulation modeling}

In this section a blended wind product obtained by combining ECMWF and SAR-derived surface wind fields will be constructed, and used to force a circulation model implemented in a southern Tyrrhenian coastal area of particular oceanographic interest. The relevance of SAR-derived winds in improving coastal circulation modeling will then be inferred.

\subsection{The coastal circulation model}

The test site chosen for this study is a coastal area located in the Tyrrhenian Sea, a western Mediterranean sub-basin where very relevant oceanographic processes take place. The basin-scale circulation yields an important interannual variability shaped by a strong seasonal cycle and energetic mesoscale features (e.g., see Artale et al., 1994; Pierini and Simioli, 1998; Schroeder et al., 2008; Vetrano et al., 2010). Local driving mechanisms are the heat, evaporative and momentum fluxes at the air-sea interface, while an important remote forcing is provided by the fluxes of modified Atlantic and Levantine intermediate water masses through the 


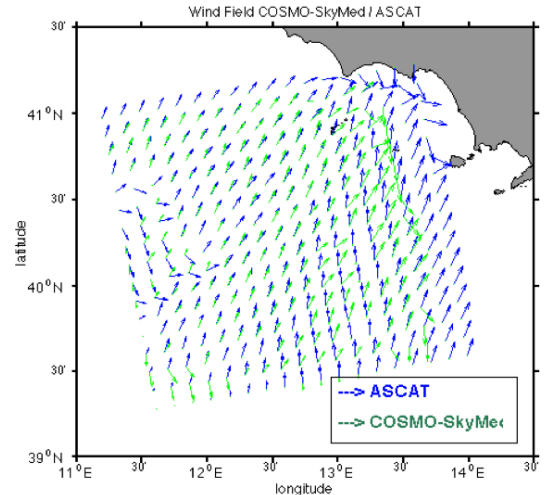

(a)

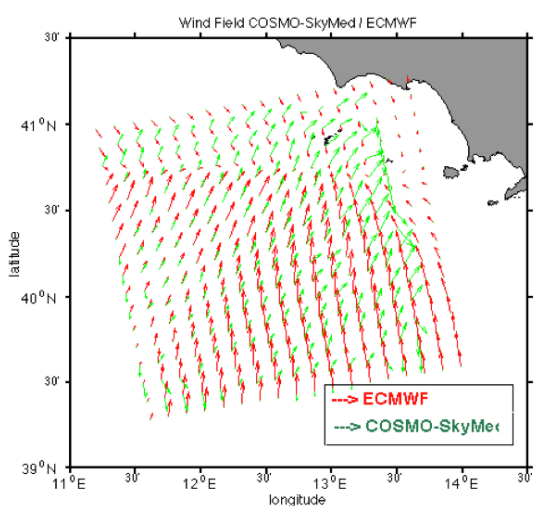

(b)

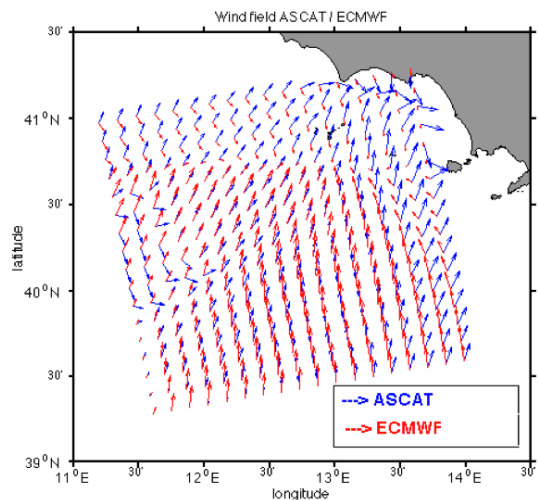

(c)

Fig. 3. Georeferenced maps of the comparisons of Fig. 2d, e, and $\mathrm{f}$ in terms of the complete surface wind vector fields.

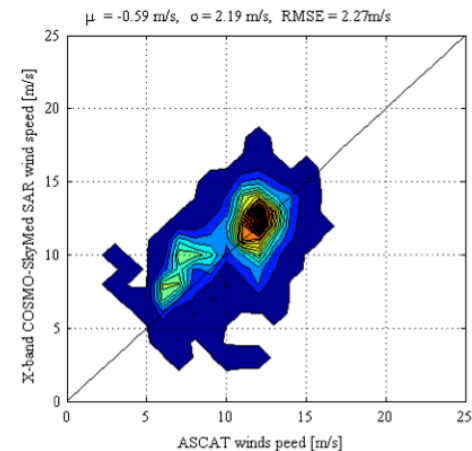

(a)

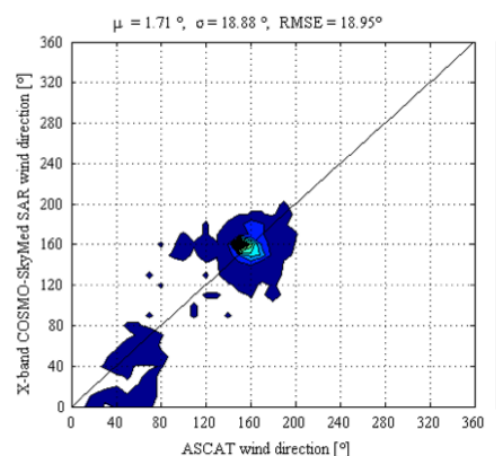

(d)
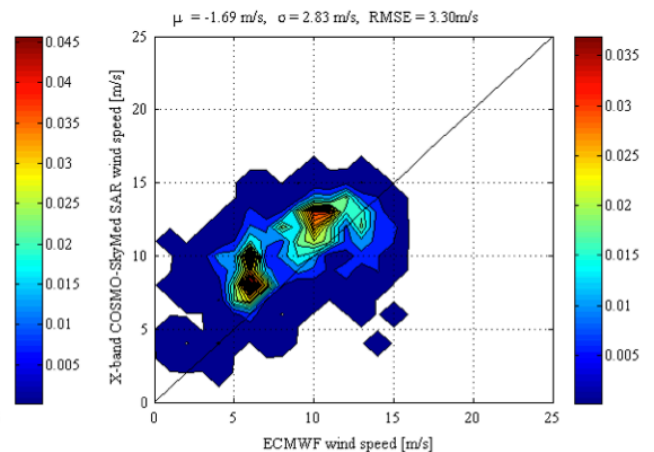

(b)
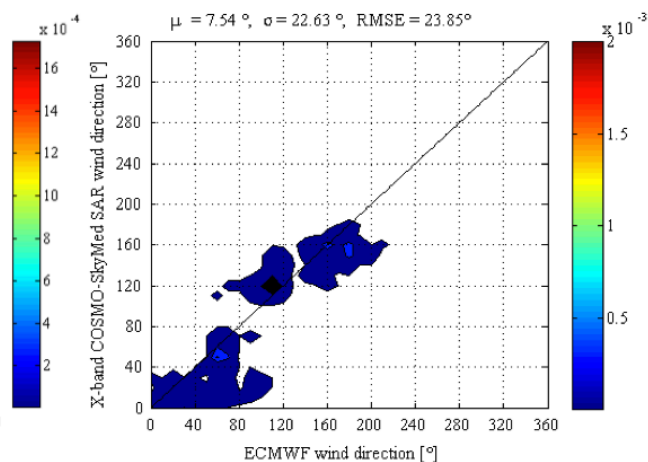

(e)

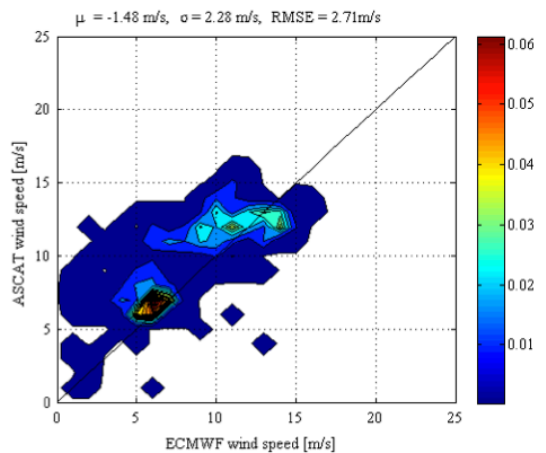

(c)

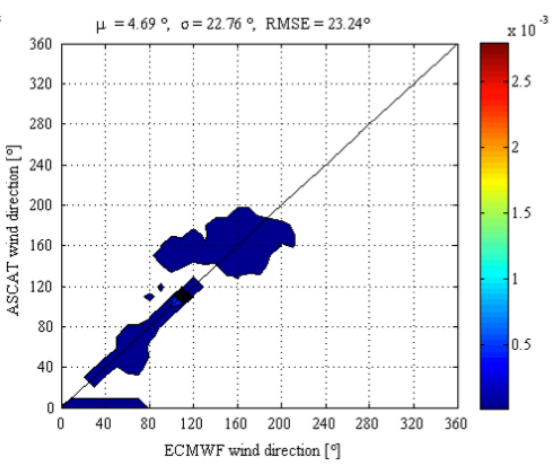

(f)

Fig. 4. Probability density scatter plots of the comparison of the X-band COSMO-SkyMed ${ }^{\circledR}$ SAR derived wind field with ASCAT scatterometer and ECMWF model reference ground truth, by considering a sub-image gridding scale of $12.5 \mathrm{~km} \times 12.5 \mathrm{~km}$. (a) Scatter plot of COSMO-SkyMed ${ }^{\circledR}$-ASCAT wind speed inter-comparison. (b) Scatter plot of COSMO-SkyMed ${ }^{\circledR}$-ECMWF wind speed inter-comparison. (c) Scatter plot of ASCAT-ECMWF wind speed inter-comparison. (d) Scatter plot of COSMO-SkyMed ${ }^{\circledR}-$ ASCAT wind direction intercomparison. (e) Scatter plot of COSMO-SkyMed ${ }^{\circledR}$-ECMWF wind direction inter-comparison. (f) Scatter plot of ASCAT-ECMWF wind direction inter-comparison.

Sardinia and Sicily straits (e.g., Pierini and Rubino, 2001; Molcard et al., 2002; Napolitano et al., 2003; Béranger et al., 2004; Gaberšek et al., 2007). In the south-eastern Tyrrhenian Sea a small semi-enclosed basin, the Gulf of Naples, is present: this is a very interesting zone, not only because it is ideal in terms of physical processes occurring in such a reg- ular geometry, but also from environmental, social and economic viewpoints. The local circulation was analyzed both through experimental (e.g., De Maio et al., 1985) and modeling studies (e.g., Gravili et al., 2001; Grieco et al., 2005; Iermano et al., 2012). 


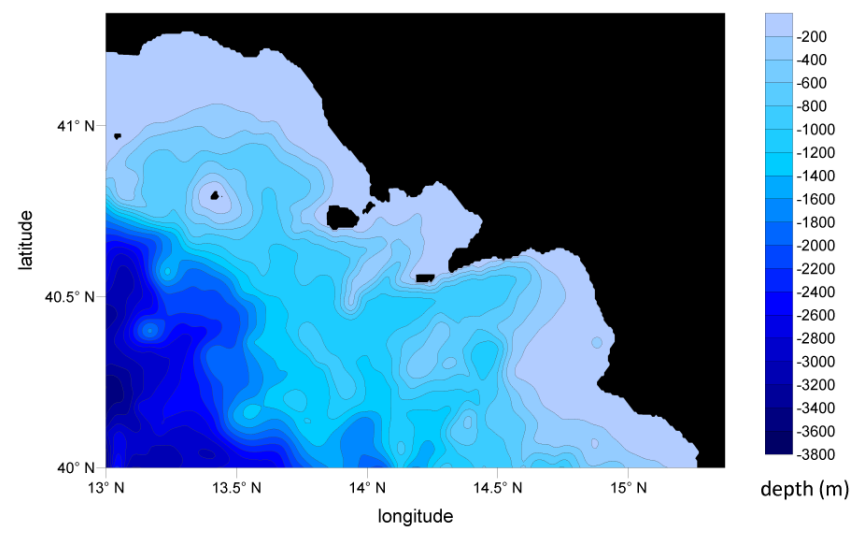

Fig. 5. Domain of integration of the coastal circulation model, with water depth.

The coastal area chosen as a test site within the Tyrrhenian Sea, where SAR-wind data have been obtained, is defined by $\lambda=13^{\circ} / 15.36^{\circ} \mathrm{E}$ and $\phi=40^{\circ} / 41.43^{\circ} \mathrm{N}$ : it includes the gulfs of Naples, Gaeta and Salerno and a wide outer buffer zone (Fig. 5) necessary to couple this model with a largerscale model of the Tyrrhenian Sea. The adopted circulation model is the POM (Blumberg and Mellor, 1987), one of the most widely used community models in coastal applications. The sigma-coordinate vertical discretization of the governing equations allows one to have a sufficiently high number of vertical levels both in shallow and deep water, a particularly advantageous feature in coastal area such as the one under investigation. Our coastal model has been one-way nested with a POM Tyrrhenian Sea model (TSM, Napolitano et al., 2013), which is, in turn, nested with the NEMO-OPA (Nucleus for European Modelling of the Ocean-Ocean PArallelise) implemented in the Mediterranean at $1 / 16^{\circ} \times 1 / 16^{\circ}$ horizontal resolution and 72 unevenly spaced vertical levels (Oddo et al., 2009). The nesting (which follows the approach of Zavatarelli and Pinardi, 2003) has required the initialization of the hydrological and dynamical structure of the coastal model with data obtained from the TSM, and the prescription, along the open lateral boundaries, of dynamical boundary conditions derived, again, from the TSM. The adopted horizontal resolution, $1 / 144^{\circ}$ (with $\Delta y \cong 772 \mathrm{~m}$ and $\Delta x \cong 579-591 \mathrm{~m}$ ), is $1 / 3$ the resolution of the TSM (for details of the nesting procedure, see de Ruggiero et al., 2013). The vertical discretization makes use of 40 sigma-levels in both models, so as to allow for a smooth nesting. As for the bottom topography, the 30" GEBCO (General Bathymetric Chart of the Oceans) data are used. Figure 6 shows an example of instantaneous current velocity maps at $1 \mathrm{~m}$ (a) and $300 \mathrm{~m}$ (b) depth obtained in autumn 2010 under ECMWF ERA Interim Reanalysis forcing. De Ruggiero et al. (2013) present a variety of scenarios simulated for different seasons, and show that the ECMWF forcing is successful in simulating dynamical processes over a scale comparable to that of the full basin, but may fail to provide appropriate forcing on the scale of the gulf, especially if strong orographic effects are present (such as those associated with Mount Vesuvius and the mountains of the Sorrento Peninsula in the Gulf of Naples).

\subsection{Simulations with a blended wind forcing that includes COSMO-SkyMed SAR data}

In this section a simulation performed with a blended wind forcing that includes SAR-wind data is presented with the aim of analyzing the capability of these data to improve coastal circulation modeling. The simulation lasts 15 days, from 10 November 2010, 00:00 UTC to 25 November 2010, 00:00 UTC. The SAR-wind data of 20 November 2010 at 05:00 UTC and 21 November 2010 at 05:00 UTC with $12.5 \mathrm{~km}$ resolution have been used to construct, together with ECMWF data, the blended wind forcing. Figure 3 shows the COSMO-SkyMed ${ }^{\circledR}$ SAR-derived surface wind velocity map (green arrows), along with the corresponding ECMWF (red arrows) and ASCAT (blue arrows) maps for the first of these two fields (20 November 2010, 05:00 UTC). The SAR-wind field of day 20 November 2010 at 05:00 UTC has been spatially interpolated with three ECMWF fields of day 20, at 00:00, 06:00, and 12:00 UTC (see the first set of three dots in the upper panel of Fig. 7). The same has been done for the second SAR-wind field (see the second set of three dots). This choice is justified by the paucity of SAR data: in doing so we have increased the weight of each available SAR-wind field without introducing an excessive spurious reduction of the temporal variability (the SAR-wind information has only been extended $6 \mathrm{~h}$ before and after the measured data).

Since the SAR data are limited to a north-western part of the integration domain (see Fig. 3), the results of the simulations are analyzed in the rectangle and in the point identified in the map of Fig. 7, where the improvement of the model results is expected to be more substantial. The three graphs of Fig. 7 show the time series of the sea surface elevation and of the two components of the surface current velocity: the signal affected by the SAR-wind forcing starts separating from that obtained with the ECMWF wind (blue line) immediately after the first SAR-wind data insertion, and the difference has remained remarkable ever since, even well after the time of the last SAR-wind data insertion. This is clearly due to the different time-dependent adjustments produced by the two forcings that have a typical time scale of few days.

In Figs. 8 and 9, the surface currents and sea surface elevation obtained with the purely ECMWF forcing (upper panels) are compared with those obtained with the blended forcing (lower panels) at the times indicated by the red arrows of the upper panel of Fig. 7. The differences are sometimes quite substantial and are not limited to the region of SAR-wind data coverage. For instance, on day 20 the strong southward current along the coasts of Latium produced by the ECMWF forcing is drastically reduced with SAR-wind data. On day 


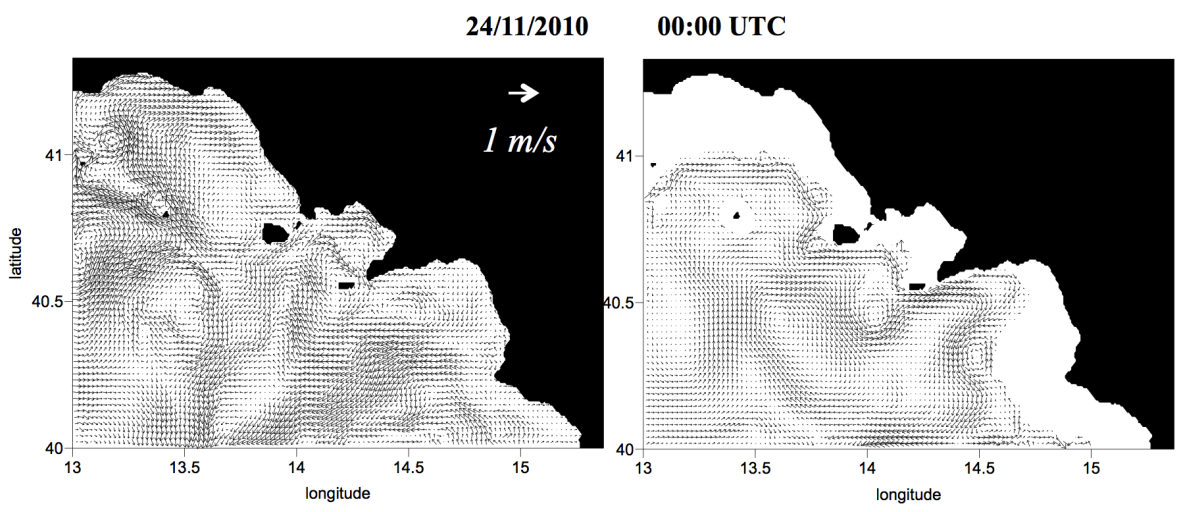

Fig. 6. Surface current velocity map (left panel) of 24 November 2010 at 00:00 UTC obtained in a simulation with ECMWF forcing and nesting with the TSM. Current velocity map at $z=300 \mathrm{~m}$ (right panel) for the same simulation at the same instant.
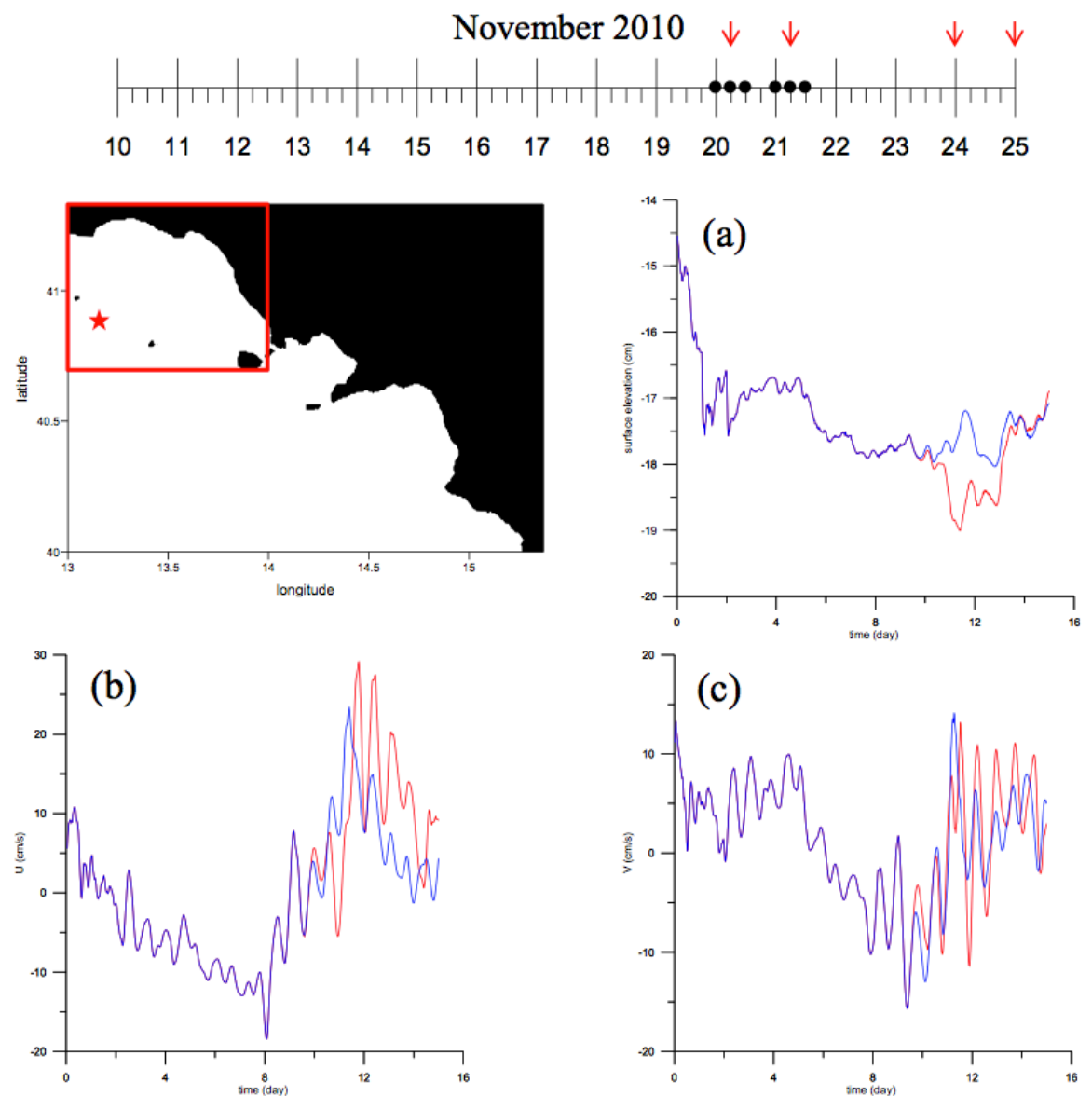

Fig. 7. Upper panel: representation of the 15-day November 2010 blended wind product (the ticks represent ECMWF winds; the dots show the instants at which COSMO-SkyMed wind data have been blended with ECMWF data; the red arrows show the time instants corresponding to the maps shown in the subsequent figures). The red rectangle inside the map represents the window in which the comparisons shown in the subsequent figures are performed. The graphs of panels (a), (b), and (c) show the time series of the sea surface elevation, of the zonal and meridional surface velocity components, respectively, sampled in the point identified by a star in the map; the blue lines refer to the simulation with the purely ECMWF forcing, the red lines to the simulation with the blended wind forcing ( $t=0$ corresponds to 10 November 2010 , 00:00 UTC). 


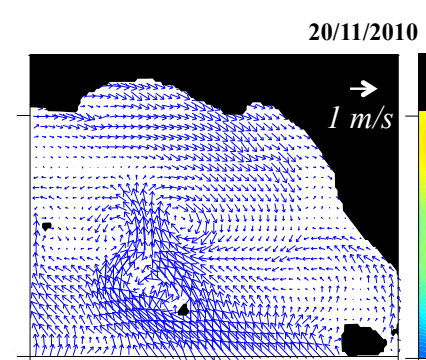

06:00 UTC

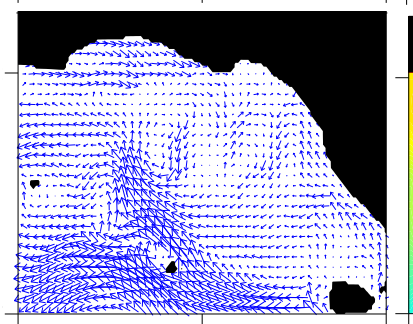

21/11/2010 06:00 UTC
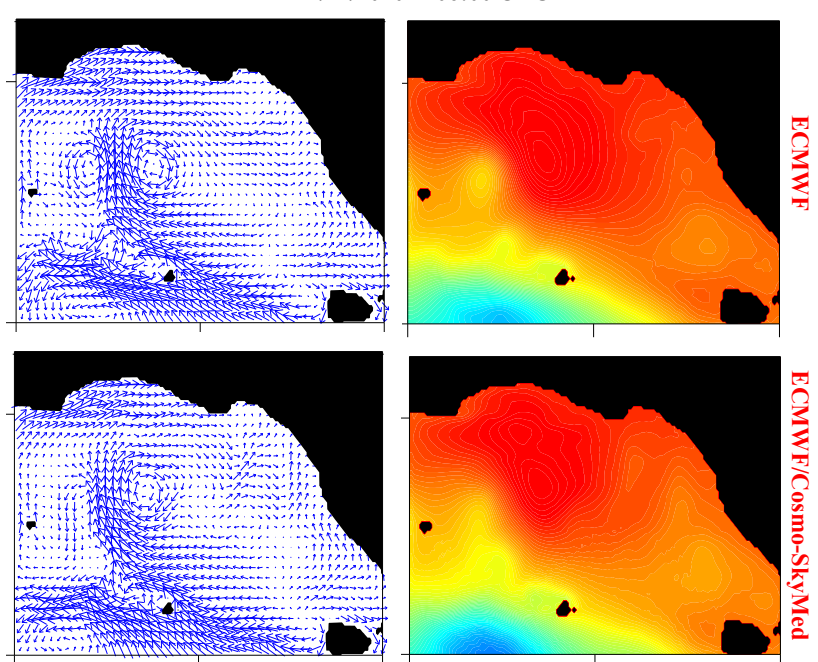

(cm)

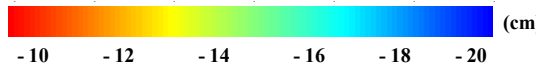

Fig. 8. First and third row: surface currents (left) and sea surface elevation (right) in the window shown in Fig. 7, respectively, at 06:00 UTC of 20 November 2010 and at 06:00 UTC of 21 November 2010 obtained in the simulation with ECMWF wind forcing. Second and fourth row: same, but obtained with blended ECMWF/COSMO-SkyMed wind forcing.

21 the strong cyclonic gyre east of the northward jet almost disappears with SAR-wind data. A similar phenomenon occurs on day 24 . On day 25 the circulation in the western half of the window changes completely with SAR data. In conclusion, our results suggest that the surface wind fields obtained from COSMO-SkyMed ${ }^{\circledR}$ SAR data could be used, together with model data (such as ECMWF), to construct a blended wind product that can serve as an alternative wind forcing for improved coastal marine circulation modeling. In fact, the SAR-based wind product is measured instead of modeled, so it bypasses all the model limitations associated with
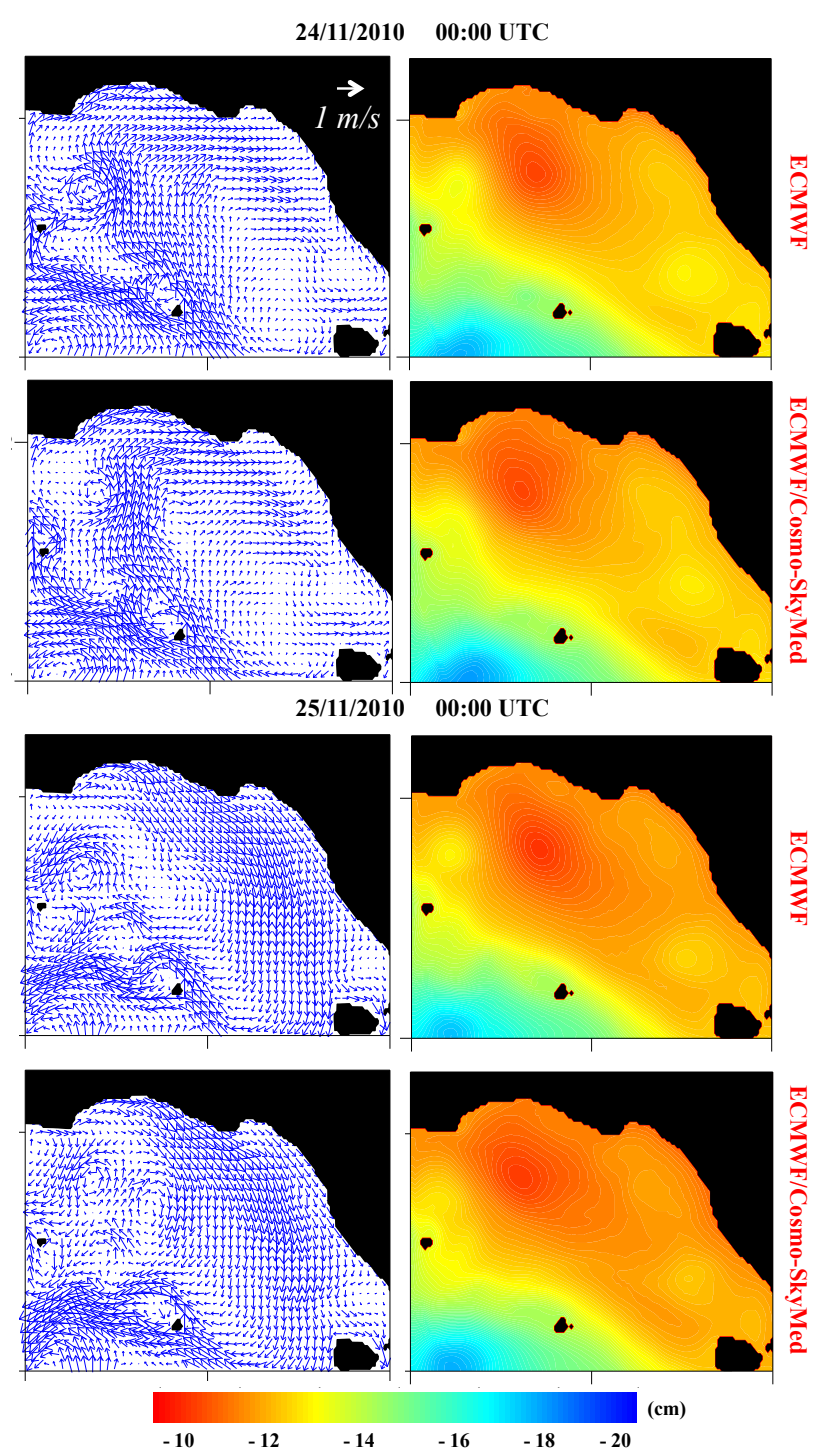

Fig. 9. First and third row: surface currents (left) and sea surface elevation (right) in the window shown in Fig. 7, respectively, at 00:00 UTC of 24 November 2010 and at 00:00 UTC of 25 November 2010 obtained in the simulation with ECMWF wind forcing. Second and fourth row: same, but obtained with blended ECMWF/COSMO-SkyMed wind forcing.

coastal environments with strong orographic features; moreover, those winds have a spatial resolution that can be considerably higher than that of modeled winds, so that more reliable simulations of mesoscale and smaller scale oceanic features can be achieved. 


\section{Conclusions}

In this paper, a feasibility study aimed at evaluating the capability of COSMO-SkyMed ${ }^{\complement}$ SAR data to provide surface wind fields that can improve coastal circulation modeling is carried out. A SAR data set $60 \mathrm{X}$-band Level 1B DGM ScanSAR Huge Region mode VV-polarized COSMO-SkyMed $^{\circledR}$ SAR data, gathered in a southern Tyrrhenian coastal area on 2010, is properly processed for wind vector field estimation purposes. Within such a framework: (1) the SAR wind speed estimation is accomplished by means of a SAR wind speed retrieval algorithm based on the azimuth cut-off procedure; (2) the SAR wind direction estimation is accomplished by means of SAR wind direction retrieval algorithm based on the DWT-MRA. The oceanographic model, which is used to simulate coastal circulation processes in a southern Tyrrhenian coastal test area, is forced by a blended wind product that includes ECMWF and SARderived winds. Our results have shown the following:

- X-band COSMO-SkyMed ${ }^{\circledR}$ SAR data effectively represent a successful resource to retrieve the wind field information at the sea surface. The consistency of X-band COSMO-SkyMed ${ }^{\circledR}$ SAR-derived wind field retrievals is effectively validated with respect to both the ASCAT scatterometer and the ECMWF ground truth. Moreover, the high-resolution accuracy of the ASCAT scatterometer wind field with respect to the ECMWF model data has been assessed, thus providing a consistent scatterometer-based reference ground truth to evaluate the consistency of X-band COSMO-SkyMed ${ }^{\circledR}$ SARbased wind field estimation products. Furthermore, experimental results take full benefits of X-band Level 1B DGM ScanSAR Huge Region COSMO-SkyMed ${ }^{\complement}$ SAR data as an alternative source of wind field estimation;

- a blended wind product based on X-band COSMO-SkyMed ${ }^{\circledR}$ SAR-retrieved surface wind data, and on other wind products (such as ECMWF model winds), can improve the simulation of wind-driven coastal circulation processes;

- despite both the limitations of available consecutive COSMO-SkyMed $^{\circledR}$ SAR acquisitions (and therefore SAR-derived wind field data) and the relatively poor spatial coverage of the adopted coastal test site, our results show that COSMO-SkyMed ${ }^{\complement}$ SAR data do represent a potentially valuable tool for improving coastal circulation modeling, which is very important for oceanographic, ecological, social and economic applications.

Acknowledgements. This work has been supported by the COSMO-SkyMed ${ }^{\circledR}$ project of the Italian Space Agency (ID 1500, contract no. I/050/09/0). The authors acknowledge the Italian Space Agency and E-geos for useful discussions. PdR, SP, and GS acknowledge also the support of the PROMETEO project of the University of Naples Parthenope.

Edited by: D. Fernández Prieto

\section{References}

Artale, V., Astraldi, M., Buffoni, G., and Gasparini, G. P.: Seasonal variability of gyre-scale circulation in the northern Tyrrhenian Sea, J. Geophys. Res., 99, 14127-14137, 1994.

Bentamy, A., Queffeulou, P., Quilfen, Y., and Katsaros, K.: Ocean Surface Wind Fields Estimated from Satellite Active and Passive Microwave Instruments, IEEE T. Geosci. Remote, 37, 2469 2486, 1999.

Béranger, K., Mortier, L., Gasparini, G. P., Gervasio, L., Astraldi, M., and Crépon, M.: The dynamics of the Sicily Strait: a comprehensive study from observations and models, Deep-Sea Res. Part II, 51, 411-440, 2004.

Blumberg, A. F. and Mellor, G. L.: A description of a threedimensional coastal ocean circulation model, Three-Dimensional Coastal Ocean Models, edited by: Heaps, N. S., AGU, Washington, DC, 1-16, 1987.

Chapron, B., Fouhaily, T. E., and Kerbaol, V.: Calibration and validation of ERS wave mode products, Inst. Fr. De Rech. pour l'Exploit de la Mer, Brest, France, Doc. DRO/OS/95-02, 1995.

De Maio, A., Moretti, M., Sansone, E., Spezie, G., and Vultaggio, M.: Outline of marine currents in the Bay of Naples and some considerations on pollutant tran sport, Il Nuovo Cimento 8C, 955-969, 1985.

De Ruggiero, P., Napolitano, E., Iacono, R., Pierini, S., and Spezie, G.: High-resolution model studies of the circulation in coastal areas of the Tyrrhenian Sea (including the Gulf of Naples), in preparation, 2013.

Du, Y., Vachon, P. W., and Wolfe, J.: Wind Direction Estimation from SAR images of the Ocean using Wavelet Analysis, Can. J. Remote Sens., 28, 498-509, 2002.

Gaberšek, S., Sorgente, R., Natale, S., Ribotti, A., Olita, A., Astraldi, M., and Borghini, M.: The Sicily Channel Regional Model forecasting system: initial boundary conditions sensitivity and case study evaluation, Ocean Sci., 3, 31-41, doi:10.5194/os-331-2007, 2007.

Gravili, D., Napolitano, E., and Pierini, S.: Barotropic aspects of the dynamics of the Gulf of Naples (Tyrrhenian Sea), Continental Shelf Res., 21, 455-471, 2001.

Grieco, L., Tremblay, L. B., and Zambianchi, E.: A hybrid approach to transport processes in the Gulf of Naples: an application to phytoplankton and zooplankton population dynamics, Continental Shelf Res., 25, 711-728, 2005.

Holzner, J. and Bamler, R.: Burst-Mode and ScanSAR interferometry, IEEE T. Geosci. Remote, 40, 1917-1934, 2002.

Horstmann, J., Koch, W., and Lehner, S.: Wind Fields Retrieved from SAR in Comparison to Numerical Models, in: Proceedings of Sixth International Winds Workshop, 7-10 May 2002, EUM P 35, ISBN 92-9110-048-1, ISSN 1023-0416, Madison, Wisconsin, USA, 2002.

Horstmann, J., Schiller, H., Schulz-Stellenfleth, J., and Lehner, S.: Global Wind Speed Retrieval From SAR, IEEE T. Geosci. Re- 
mote, 41, 2277-2286, 2003.

Iermano, I., Liguori, G., Iudicone, D., Buongiorno Nardelli, B., Colella, S., Zingone, A., Saggiomo, V., and Ribera d'Alcalà, M.: Filament formation and evolution in buoyant coastal waters: Observation and modelling, Progr. Oceanogr., 106, 118-137, 2012.

Italian Space Agency (ASI) - COSMO-SkyMed Mission: COSMO-SkyMed System Description and User Guide, Online, available at: http://www.cosmo-skymed.it/docs/ ASI-CSM-ENG-RS-093-A-CSKSysDescriptionAndUserGuide. pdf, 2007.

Jackson, C. R. and Apel, J. R.: Synthetic Aperture Radar (SAR) marine user's manual, National Oceanic and Atmospheric Administration (NOOA), Washington, DC, USA, 2004.

Janssen, P.: The Interaction of Ocean Waves and Wind, Cambridge University Press, UK, 2004.

Kerbaol, V. and Collard, F.: SAR-derived coastal and marine applications: From research to operational products, IEEE J. Oceanic Eng., 30, 472-486, 2005.

Kerbaol, V., Chapron, B., and Vachon, P. W.: Analysis of ERS1/2 Synthetic Aperture Radar wave mode imagettes, J. Geophys. Res., 103, 7833-7846, 1998.

Korsbakken, E., Johannessen, J. A., and Johannessen, O. M.: Coastal Wind Field Retrievals from ERS Synthetic Aperture Radar Image, J. Geophys. Res., 103, 7857-7874, 1998.

Lee, P. H. Y., Barter, J. D., Beach, K. L., Hindman, C. L., Lake, B. M., Rungaldier, H., Shelton, J. C., Williams, A. B., Yee, R., and Yuen, H. C.: X band microwave backscattering from ocean waves, J. Geophys. Res., 100, 2591-2611, 1995.

Mallat, S. G.: A Theory for Multiresolution Signal Decomposition: the Wavelet Representation, IEEE T. Pattern Anal., 11, 674-693, 1989.

Mellor, G. L.: Users guide for a three-dimensional, primitive equation, numerical ocean model, Prog. in Atmos. and Ocean Sci., Princeton University, 53 pp., 2003.

Migliaccio, M. and Reppucci, A.: A review of sea wind vector retrievals by means of microwave remote sensing, in: Proceedings of the European Microwave Association 2006, 2, 136-140, 2006.

Migliaccio, M., Montuori, A., and Nunziata, F.: X-band Azimuth cut-off for wind speed retrieval by means of COSMO-SkyMed SAR data, in: Proceedings of IEEE/OES Baltic International Symposium, Klaipeida, Lithuania, 8-10 May 2012, 1-4, 2012.

Molcard, A., Gervasio, L., Griffa, A., Gasparini, G. P., Mortier, L., and Ozgokmen, T. M.: Numerical investigation of the Sicily Channel dynamics: density currents and water mass advection, J. Mar. Sys., 36, 219-238, 2002.

Montuori, A., Migliaccio, M., and Nunziata, F.: Wind Speed Estimation in the Tyrrhenian Sea by Means of X-band COSMOSkyMed SAR Data, in: Proceedings of Tyrrhenian Workshop on Advances in Radar and Remote Sensing 2012, 12-14 September 2012, Naples, Italy, 2012.

Napolitano, E., Sannino, G., Artale, V., and Marullo, S.: Modeling the baroclinic circulation in the area of the Sicily channel: The role of stratification and energy diagnostics, J. Geophys. Res., 108, 3230, doi:10.1029/2002JC001502, 2003.
Napolitano, E., Iacono, R., and Marullo, S.: The 2009 surface and intermediate circulation of the Tyrrhenian Sea as assessed by an operational model, in: The Mediterranean Sea: Temporal Variability and Spatial Patterns, AGU Book Series, edited by: Borzelli, G., Malanotte-Rizzoli, P., Gacic, M., and Lionello, P., in press, 2013.

Nunziata, F., Gambardella, A., and Migliaccio, M.: A simulator for SAR sea surface waves imaging, in: Proceedings of IEEE Int Geosci. Remote Se. 2007, Barcellona, Spain, 23-27 July 2007, 786-789, 2007.

Oddo, P., Adani, M., Pinardi, N., Fratianni, C., Tonani, M., and Pettenuzzo, D.: A nested Atlantic-Mediterranean Sea general circulation model for operational forecasting, Ocean Sci., 5, 461-473, doi:10.5194/os-5-461-2009, 2009.

Pierini, S. and Rubino, A.: Modeling the oceanic circulation in the area of the Strait of Sicily: the remotely-forced dynamics, J. Phys. Oceanogr., 31, 1397-1412, 2001.

Pierini, S. and Simioli, A.: A wind-driven circulation model of the Tyrrhenian Sea area, J. Mar. Sys., 18, 161-178, 1998.

Schiavulli, D., Sorrentino, A., and Migliaccio, M.: An Automatic Procedure for Scalloping suppression and Homogeneity Analysis of Sea X-band CSK SAR Images, Atti della Fondazione Giorgio Ronchi, Anno LXVII, 66, 27-38, 2011.

Schiavulli, D., Sorrentino, A., and Migliaccio, M.: An Innovative Technique for Postprocessing Descalloping, IEEE Geosci. Remote S., 10, 424-427, 2012.

Schroeder, K., Taillandier, V., Vetrano, A., and Gasparini, G. P.: The circulation of the western Mediterranean Sea in spring 2005 as inferred from observations and from model outputs, Deep-Sea Res. Part I, 55, 947-965, 2008.

Schulz-Stellenfleth, J. and Lehner, S.: Measurement of 2-D sea surface elevation fields using complex synthetic aperture radar data, IEEE T. Geosci. Remote, 42, 1149-1160, 2004.

Vallis, G. K.: Atmospheric and Oceanic Fluid Dynamics, Cambridge University Press, 2006.

Vetrano, A., Napolitano, E., Iacono, R., Schroeder, K., and Gasparini, G. P.: Tyrrhenian Sea circulation and water mass fluxes in spring 2004: Observations and model results, J. Geophys. Res., 115, C06023, doi:10.1029/2009JC005680, 2010.

Yang, X., Li, X., Pichel, W. G., and Li, Z.: Comparison of Ocean Surface Winds From ENVISAT ASAR, MetOp ASCAT Scatterometer, Buoy Measurements, and NOGAPS Model, IEEE Geosci. Remote, 49, 4743-4750, 2011.

Zavatarelli, M. and Pinardi, N.: The Adriatic Sea modelling system: a nested approach, Ann. Geophys., 21, 345-364, doi:10.5194/angeo-21-345-2003, 2003. 